doi: 10.1111/1753-6405.12544

\section{The development and validation of a new survey tool: the first step to profiling New Zealanders' eating styles and moving patterns}

Olivia Maclaren, ${ }^{1}$ Lisa Mackay, ${ }^{2}$

Grant Schofield, ${ }^{2}$ Caryn Zinn ${ }^{2}$

1. School of Nursing, Eastern Institute of Technology, New Zealand

2. School of Sport and Recreation, Auckland

University of Technology, New Zealand

Nutrition and physical activity behaviours are well-known determinants of health. ${ }^{1-7}$

Current New Zealand (NZ) surveys monitoring these important behaviours are designed around understanding whether or not best practice guidelines ${ }^{8}$ have been met. ${ }^{9-13}$ These behaviours have been predominantly quantified by a 24 -hr diet recall, ${ }^{9}$ combined with a food frequency questionnaire looking at specific food consumption, ${ }^{10,11}$ and questionnaires that examine the intensity and time spent in physical activity. ${ }^{10-12}$

Current population-wide surveys in NZ that examine nutrition and physical activity fail to adequately examine the pattern and context to these behaviours. In everyday life, it is unlikely that many people weigh and measure their food on a regular basis, or consider the frequency of their consumption of individual foods. Similarly, it is unlikely that they would consider their physical activity (athletes may be the exception) with such precision as daily duration and intensity. Nutrition and physical activity behaviours are complex and are influenced by the physiology, ecological and social environments of the individual. ${ }^{14,15}$ Different philosophies around nutrition and physical activity behaviours are not fully understood and have not been well examined in population-wide studies.

This work aimed to develop a new and straightforward tool to move beyond the simple quantification of food consumption and physical activity by investigating the broader context to eating and moving. Developing a new tool is the first step to enable the examination of whether someone follows a specific eating philosophy (e.g. plant-based, Mediterranean, lowcarbohydrate or low-fat approach), and how, where, and with whom they are physically active. A broader understanding of the common approaches to eating and moving at a population level will enable a more comprehensive understanding of the relationship between these behaviours and health.

\section{Survey development}

Content validity was a crucial part of the survey development process. The questions underwent two reviews and modifications by an expert panel that included a registered dietitian, a public health academic, an exercise physiologist and two epidemiologists; all employed in academic institutions. Furthermore, to improve the content validity, verbal feedback was obtained from participants involved in the test-retest reliability assessment (described below).

During initial development, the primary inclusion criteria for each question was the ability to differentiate a range of eating and physical activity approaches. Additional criteria were the ease of interpretation, suitability for online use, conciseness and reliability. The final survey was structured into two parts: basic demographic questions; and nutrition and physical activity questions.

The nutrition questions examined the approximate weekly consumption (over the previous four weeks) of major food groups (grains, dairy, eggs, fats, red meat, white meat, fish, fruit, vegetables and nuts) and processed foods (processed meats, snack foods, confectionery, sugary drinks, takeaways and protein powder). Dairy was further distinguished as low-fat or full-fat, separate options were included for starchy vegetables and non-starchy vegetables, and fat sources were itemised as butter, margarine, processed or non-processed oils. In addition, a set of questions investigated the participants' beliefs in their food choices and were designed to distinguish whether participants prioritised eating low-fat options; high-fat options; or processed, convenient foods. A set of questions also examined participants' attitudes to weight loss and weight gain to provide some idea of the motivation for their dietary behaviours.

The physical activity questions included exercise (planned, structured and repetitive physical activity ${ }^{16}$ ) and non-exercise physical activity (unstructured activity). The first set of questions examined non-exercise activity (work-related activity demands, transport modes, evening activity and sitting time). The second set of questions examined approximate weekly engagement in different types of exercise (short or long duration vigorous-intensity, moderate-intensity, sportrelated, strength and resistance training, and flexibility); as well as the social context of these exercise activities.

\section{Psychometrics}

This involved content validity assessment (as outlined above) and a pilot study to examine test-retest reliability. Participants were recruited from a NZ academic institution and associated contacts for the pilot. A repeated measures online approach $(9$ days, $\mathrm{SD} \pm 4$ days between surveys) was used. Percentage agreement and Cohen's linear ${ }^{17}$ and quadratic ${ }^{17,18}$ weighted kappas were calculated. Strength of agreement thresholds ${ }^{19}$ were assigned to the quadratic weighted kappa values.

\section{Results}

Content validity appeared to be robust from analysis of participant and expert panel feedback. Twenty-two participants (17 females) completed the test-retest reliability pilot study (mean age $51 \mathrm{SD} \pm 11$ years). Participants were primarily European (90\%) and in full- or part-time employment (59\%). It is acknowledged that this is a not a fully representative sample of the NZ population and is therefore considered a pilot study.

For the test-retest reliability (42 questions across nutrition and physical activity), five questions (11.9\%) showed perfect agreement, 19 (45.2\%) showed excellent strength of agreement, 16 (38.1\%) showed fair-to-good strength of agreement, and two (4.8\%) showed poor strength of agreement. The two questions that showed poor agreement were on frequency of soft drink consumption and evening household activities. Further review and amendments are required with these questions.

Overall, the majority (40) of the survey items showed fair-to-excellent test-retest reliability within the pilot study sample. Additionally, the content was considered to be valid for the survey aims. All indirect nutrition and physical activity assessments have methodological limitations, and web-based administration is likely to share similar issues to traditional paper-based counterparts. ${ }^{20}$

A four-week recall period was stipulated to provide a reasonably stable period for analysis. The time period between surveys was designed to limit participants' recall of responses; but at the same time it maintained the stability of their responses. Five questions were answered identically between rounds, 
which suggests that these patterns were either very reliable or potentially some recall between surveys was occurring. A slightly longer period between surveys may have minimised any recall; however, a longer period would have changed the recall window and potentially the participants' eating patterns.

\section{Implications}

The next step in the survey development process is to implement the survey within a large population sample and explore patterns to the data. This will hopefully identify common patterns in New Zealanders' approach to eating and moving. If distinct patterns become evident, associations with health and wellbeing may be elucidated. In addition, these patterns may enable more targeted research and interventions focusing on the philosophies governing food choice and activity patterns.

For additional details or copies of the final survey and SPSS syntax for Cohen's weighted kappa, contact the corresponding author.

\section{References}

1. World Health Organization. Obesity: Prevention and Managing the Global Epidemic: Report of a WHO Consultation. WHO Technical Report Series No. 894. Geneva (CHE):WHO; 2000.

2. World Health Organization. Global Recommendations on Physical Activity for Health [Internet]. Geneva (CHE): WHO; 2010 [cited 2016 Jan 10]. Available from: http:// www.who.int/dietphysicalactivity/publications/ recommendations5_17years/en/

3. Steyn NP, Mann J, Bennett PH, Temple N, Zimmet $\mathrm{P}$, Tuomilehto J, et al. Diet, nutrition and the prevention of type 2 diabetes. Public Health Nutr. 2004;7(1a):147-65.

4. ReddyKS, Katan MB. Diet, nutrition and the prevention of hypertension and cardiovascular diseases. Public Health Nutr. 2004;7(1a):167-86.

5. Key TJ, Schatzkin A, Willett WC, Allen NE, Spencer EA, Travis RC. Diet, nutrition and the prevention of cancer. Public Health Nutr. 2004;7(1a):187-200.

6. Owen N, Healy GN, Matthews CE, Dunstan DW. Too much sitting: The population health science of sedentary behavior. Exerc Sport Sci Rev. 2010;38(3): 105-13.

7. Penedo FJ, Dahn JR. Exercise and well-being: A review of mental and physical health benefits associated with physical activity. Curr Opin Psychiatry. 2005;18(2): 189-93.

8. Ministry of Health. Eating and Activity Guidelines for New Zealand Adults [Internet]. Wellington (NZ): Government of New Zealand; 2015 [cited 2015 Nov 23]. Available from: http://www.health.govt.nz/publication/eatingand-activity-guidelines-new-zealand-adults

9. University of Otago and Ministry of Health. A Focus on Nutrition: Key Findings of the 2008/09 New Zealand Adult Nutrition Survey [Internet]. Wellington (NZ): Government of New Zealand; 2011 [cited 2014 Jan 5]. Available from: http://www.health.govt.nz/

10. Ministry of Health. A Potrait of Health. Key Results of the 2006/07 New Zealand Health Survey [Internet]. Wellington (NZ): Government of New Zealand; 2008 [cited 2014 Jan 5]. Available from: http://www.health. govt.nz/publication/portrait-health-key-results-200607-new-zealand-health-survey
11. Research and Evaluation Unit Health Promotion Agency. 2012 Health and Lifestyles Survey [Internet]. Wellington (NZ): Health Promotion Agency; 2012 [cited 2015 Sep 10]. Available from: www.hpa.org.nz

12. BascandG. TimeUseSurvey:2009/10:Key Facts [Internet]. Wellington (NZ): Statistics New Zealand; June 2011 [cited 2016 Jan 25]. Available from: http://www.stats. govt.nz/browse_for_stats/people_and_communities/ time use/TimeUseSurvey HOTP2009-10.aspx

13. Sport New Zealand. Sport and Active Recreation in the Lives of New Zealand Adults. 2013/14 Active NewZealand Survey Results [Internet]. Wellington (NZ): Government of New Zealand; 2015 [cited 2016 Feb 2]. Available from: http://www.sportnz.org.nz/managing-sport/ research/201314-active-nz-survey-2

14. Galef BG Jr. Food selection: Problems in understanding how we choose foods to eat. Neurosci Biobehav Rev. 1996;20(1):67-73.

15. Bauman AE, Reis RS, Sallis JF, Wells JC, Loos RJF, Martin BW. Physical Activity 2: Correlates of physical activity: Why are some people physically active and others not? Lancet. 2012;380(9838):258-71.

16. Caspersen CJ, Powell KE, Christenson GM. Physical activity, exercise, and physical fitness: Definitions and distinctions for health-related research. Public Health Rep. 1985;100(2):126-31.

17. Sim J,WrightCC. The kappa statistic in reliability studies: Use, interpretation, and sample size requirements. Phys Ther. 2005;85(3):257-68.

18. Fleiss JL, Cohen J. The equivalence of weighted kappa and the intraclass correlation coefficient as measures of reliability. Educ Psychol Meas. 1973;33(3):613-9.

19. Salerno DF, Franzblau A, Armstrong TJ, Werner RA, Becker MP. Test-retest reliability of the Upper Extremity Questionnaireamong keyboard operators. EducPsychol Meas. 2001;40(6):655-66.

20. Illner AK, Freisling $H$, Boeing $H$, Huybrechts I, Crispim SP, Slimani N. Review and evaluation of innovative technologies for measuring diet in nutritional epidemiology. Int J Epidemiol. 2012;41(4):1187-203.

Correspondence to: Ms Olivia Maclaren, School of Nursing, Eastern Institute of Technology, Private Bag 1201, Hawkes Bay Mail Centre, Napier 4142, Hawkes Bay, New Zealand; e-mail: omaclaren@eit.ac.nz 